\title{
RELATIONSHIP BETWEEN PESTICIDE USE AND CLIMATE CHANGE FOR CROPS
}

\author{
Bhakta R. Palikhe, MSc. Ento. ${ }^{12}$
}

\begin{abstract}
The use (and abuse) of pesticides has increased to combat insect-pests and diseases. However, the major causes concern of are the undesirable side effects of these chemicals on biodiversity, environment, food quality and human health. Climate change will have important implications for insect conservation and pest status. Climate and weather can substantially influence the development and distribution of insects. Most of the warming over the last 50 years is likely to have been due to man-made activities. Anthropogenically induced climatic change arising from increasing levels of atmospheric greenhouse gases would, therefore, be likely to have a significant effect on agricultural insect pests. Current best estimates of changes in climate indicate an increase in global mean annual temperatures of 1[0] C by 2025 and 3[0]C by the end of the next century. Such increases in temperature have a number of implications for temperature-dependent insect pests. The Assessment investigates the relationship between pesticide use and climate for crops that require relatively large amounts of pesticide. This paper describes such input-driven agriculture, the problem of pests and diseases and the unsustainable agricultural practices that it leads to, and the socio-economic and health externalities resulting in farmer's distress in pesticide hot spots. To protect ourselves, our economy, and our land from the adverse effects of climate change, we must ultimately dramatically reduce emissions of carbon dioxide and other greenhouse gases. The causes of anthropogenic climate change are broad and often difficult to address. There is no single solution to this complex problem, but numerous opportunities exist for reducing problems of climate change. The issue of climate change is one of the most profound challenges of our time, and we believe it is a challenge that can be met.
\end{abstract}

Key Words: Climate change, Crops, Pesticides, Insect pests, Diseases

\section{Introduction}

The Environmental Protection Agency (EPA or USEPA) defines pesticide as "any substance or mixture of substances intended for preventing, destroying, repelling, or mitigating any pest". A pesticide may be a chemical substance or biological agent (such as a virus or bacteria) used against pests. Farmers in the hot spots are over burdened with increasing costs of cultivation, a deleterious credit system, and declining productivity, increased incidences of pests and diseases, and spurious pesticides. The sole reliance on chemical pesticides for plant protection has created serious problems. In addition, problems of pest outbreaks, resistance and resurgence of pests demand more pesticides.

Pesticides have been the centre of controversy for a long time and are associated with risks to human health and/or to the environment. On the other hand, society accepts these risks within certain limits as there are also benefits linked to the use of pesticides, in particular in agricultural production. Overuse of pesticides has brought about a decline in the bio-diversity of non-target organisms in the hot spots. The respondents in the hot spots revealed that a significant decline in population of birds, earthworms, natural predators like green lacewing, Chrysoperia carnea, lady bird beetles, spiders, Apanteles spp., Trichogramman spp., Cheloanus, black burni, etc., was noticed in their field. Pesticides are necessary but should

\footnotetext{
${ }^{12}$ Registrar of Pesticides, Pesticide Registration and Management Office, Plant Protection Directorate of Department of Agriculture, Harihar Bhawan. Email: pesticide@wlink.com.np
} 
only be part of a total pest control program, not like entire program. Sustainable farming is a management-intensive method of growing crops at a profit while concurrently minimizing negative impact on the environment, improving soil health, increasing biological diversity, and controlling pests. Sustainable agriculture is dependent on a whole-system approach, having as its focus on the long term health of the land .One should favor the philosophical definition: "A farmer should live as though he was going to die tomorrow, but he should farm as though he was going to live forever."

Greenhouse gas emissions have the same impact on the atmosphere whether they originate in Washington, London, Beijing or Nepal. Consequently, action by one country to reduce emissions will do little to slow global warming unless other countries act as well. Ultimately, an effective strategy will require commitments and action. The science is clear: climate change is happening, and it is linked directly to human activity. Global warming poses an extraordinary challenge. The world's leading atmospheric scientists tell us that a gradual warming of our climate is underway and will continue. This long-term warming trend poses serious risks to our economy and our environment. It poses even greater risks to many other nations, particularly poorer countries that will be far less able to cope with a changing climate

It is the greatest environmental challenge of the 21st century. But what do we truly know about global climate change? And what can we do about it? Evidence shows that global climate change is occurring. Research and debate continue on the role of increasing atmospheric concentrations of greenhouse gases in influencing climate change. Many sectors are or will be influenced by changing climate and climate variability, including increasing global temperatures, changing precipitation patterns, and increased frequency of unusual weather events. Agriculture and the world's supply of food and fiber are particularly vulnerable to such climate change. Effects of Climate Change and Variability on the Agricultural Production Systems provides an integrated assessment of global climate change's impact on agriculture at the farm level, in the context of farm level adaptation decisions.

Global climate change is arguably the most severe problem that the World faces today. Our climate influences every aspect of life on this planet from our ability to produce food and therefore our future development, to the distribution of biomes and the level of biodiversity that exists in the world - much of which remains scientifically unclassified or unknown. The earth's climate has changed over the last century and there is new and stronger evidence that most of the warming observed the last 50 years is attributable to human activities. The degree to which climate change affects our lives must not be taken lightly. Take for example the increase in extreme weather conditions around the World producing devastating droughts in some regions, flooding in others and a generally greater propensity for cyclones, tornadoes and hurricanes due to increased oceanic temperatures. Many of us will be fortunate enough to never experience the destructive forces of nature but if we continue to upset natures, various equilibrium and these events could become the norm for majority of the world's population. It is important that developing countries have their own capacity to assess their national vulnerability to climate change and plant adaptation strategy accordingly. Assessment of vulnerability requires an estimate of the impacts of climate change, which in turn is based on scenarios of future climate.

Human beings are at the center of concerns for sustainable development. They are entitled to a healthy and productive life in harmony with nature. The average surface temperature has increased by about $0.6^{\circ} \mathrm{C}\left(1^{\circ} \mathrm{F}\right)$. Snow cover and ice extent have decreased. The sea level has risen by 10 to $20 \mathrm{~cm}$ ( 4 to 8 "). UNEP has declared the theme for the year 2007 which is: 
Melting ice-a hot topic? , considering the importance of the theme, the farmers, user groups and all stakeholders throughout the world accept they have a duty to steward the biodiversity and land, which they farm. Climate change is a global challenge and requires a global solution.

\section{Objectives}

- To assess and understand the relationship between pesticide usage and climate change (commonly called global warming) for crops

- To make aware on the impact of pesticides on the biodiversity and productivity

- To raise awareness and seek solutions of agriculture related environmental issues for ensuring a safe (minimizing the use of environment prone chemicals, pesticides, etc) and sustainable agricultural development.

\section{Situation Problems}

There is a regulatory infrastructure established for the management of pesticides in Nepal. Pesticide management involves the regulatory control, proper handling, supply, transport, storage, application, use and waste management, and disposal of pesticides to minimize adverse environmental effects and human exposure. The problem of pesticide misuse in Nepal is a well-known and widely-held concern for many Nepali officials, researchers, trainers' journalists and environmentalists. Once released into the environment, pesticides tend to build up in the fat tissues of living organism, causing serious harm to the health and a potential loss of bio-diversity. This is an especially important problem in Nepal. Until now, costs of environmental problems and farmer's health impairments have not yet been included in the total cost of rice productions in the agricultural sector .This opportunity costs contribute significantly to a decrease in rice farmer's profits. The environmental costs of pesticide misuse are potentially huge.

In Nepal, as most of the other developing countries in the region, the capabilities, expertise and resources to fully implement the regulation is limited. Therefore, the rate of success of effective adoption of alternative chemical options through awareness and promotion is minimal in developing countries. The inherent weakness in the field infrastructure and the capacity to carry out effective awareness campaigns further retarded the promotion of use of alternative chemical options. The idea of biodiversity and its economic value has not been addressed adequately in Nepal. There are serious data gaps observed due to lack of capability and capacity in monitoring the relationship between pesticide usage and climate change for crops in Nepal. This demands an organized survey to be conducted in Nepal with uniform methodology ensuring QA/QC.

\section{Impact of Agriculture Today}

Changes in the incidence and severity of agricultural pests, diseases, soil erosion, troposphere ozone levels, as well as changes in extreme events such as drought, floods, are largely unmeasured or uncertain and have not been incorporated in estimates of impacts. These omitted effects could results the true impacts of climate change on agriculture.

It seems obvious that any significant change in climate on a global scale should impact local agriculture, and therefore affect the world's food supply. Agriculture of any kind is strongly influenced by the availability of water. Climate change will modify rainfall, evaporation, runoff, and soil moisture storage. Changes in total seasonal precipitation or in its pattern of variability are both important. 
Agriculture contributes to climate change in a number of ways. Agriculture can make an important contribution to climate change mitigation while providing benefits to both farmers and the general public. Climate change may allow pest migration or population expansions which may adversely affect agricultural productivity, profitability and possibly even viability. Relationship between climate changes and agriculture is of particular importance as the world population and world food production showing imbalance under pressure. Soil degradation has already reduced global agricultural productivity by 13 percent in the last 50 years. Flowering patterns, breeding behaviors and the timing of migrations are all undergoing change. The distribution of plants, insects, animals and even soil bacteria is shifting rapidly. For every 1 degree increase in temperature, the researchers say, crop yields drop by about 3 percent to 5 percent, and the decline is clearly caused by human activity.

Can plants and creatures adapt fast enough to survive such rapid changes? If ecosystem relationships become disconnected and ecological processes break down; we will eventually suffer as well. Our food is a synthesis of soil, sunlight and rain. We depend on the biological diversity, ecological processes and powerful global currents of wind and water that are the operating systems of all life on Earth. Signs that these operating systems are faltering should be a wake-up call.

In general, Methyl Bromide (MB) used for quarantine treatment is for control of quarantine pests that are defined in a list available with the International Plant Protection Convention (IPPC).MB is highly toxic and also harmful to the ozone layer, but its limited use in fumigation is still allowed. Nepal finalized and adopted its Ozone Regulations only in 2002.

\section{Implications of climate change for pests and diseases}

Conditions are more favorable for the proliferation of insect pests in warmer climates. Longer growing seasons will enable insects such as grasshoppers to complete a greater number of reproductive cycles during the spring, summer, and autumn. Warmer winter temperatures may also allow larvae to winter-over in areas where they are now limited by cold, thus causing greater infestation during the following crop season. Altered wind patterns may change the spread of both wind-borne pests and of the bacteria and fungi that are the agents of crop disease. Crop-pest interactions may shift as the timing of development stages in both hosts and pests is altered. The possible increases in pest infestations may bring about greater use of chemical pesticides to control them, a situation that will require the further development and application of integrated pest management techniques.

There is a fine balance between pests and disease-causing organisms (known as pathogens) and their host plants. It is possible however to make two generalizations: stressed trees are more susceptible to insect pests and diseases, and the majority of insect pests that currently affect are likely to benefit from climate change as a result of increased summer activity and reduced winter mortality. Some insect pests that are currently present at low levels, or that are not considered a threat at this time, may become more prevalent.

\section{Insect pests}

- Climate change is likely to alter the balance between insect pests, their natural enemies and their hosts

- One of the most important effects of climate change will be to alter the synchrony between host and insect pest development, particularly in spring, but also in autumn; the predicted rise in temperature will also generally favor insect development and winter survival, although there will be some exceptions. 
- Changes have already been observed in the distribution of native butterfly populations.

\section{Fungal diseases}

- The impact on pathogens whose reproduction or dispersal is clearly affected by temperature is relatively predictable.

- Warmer summers may in particular favor certain thermophilic rust fungi

- Warmer winters may increase the activity of some weak pathogens

- An increased incidence of summer drought would probably favor diseases caused by fungi whose activity is dependent on host stress, particularly root pathogens.

\section{Insect populations}

Most studies have concluded that insect pests will generally become more abundant as temperatures increase, through a number of inter-related processes, including range extensions and phenological changes, as well as increased rates of population development, growth, and migration and over-wintering.

Global warming will increase pest populations, including weeds, invasive species, insects, and insect-borne diseases, which will likely lead to large increases in the use of pesticides. The effects of climate change are already beginning to be seen, and will continue to be seen for years to come. Without drastic actions to curb global warming, the current course we are heading on will lead to booms in pest populations and pesticide use. In plant communities, high levels of carbon dioxide stimulate the growth of invasive plant species more than native species. Additionally, as carbon dioxide increases, herbicides may become less effective at controlling invasive weeds. In addition to increasing weed populations; global climate change is expected to increase the frequency and the intensity of insect outbreaks through direct effects of climate change on insect populations, as well as through disruption of community interactions.

Researchers have found that insect species that adapt to warmer climates also will increase their maximum rates of population growth, meaning that global warming will likely lead to increased insect populations. The study's say that this "warmer is better" and phenomenon is likely to have widespread effects on agriculture, public health and conservation.

With the boom in insect populations, scientists also hypothesize that there will be increases in insect-borne diseases such as malaria, dengue fever, and viral encephalitis. Scientists believe that climate change will increase disease transmission by shifting insects' geographic range, increasing reproductive and biting rates of the insects, and by shortening the pathogen incubation period

Physiological and biochemical changes induced in host crop plants by rising $\mathrm{CO} 2$ may affect feeding patterns of pest insects. Compilation of climatic thresholds for phonological development of pest insects reveals the potential for shifts in pest behavior induced by global warming and other climatic change. Generation times may be reduced, enabling more rapid population increases to occur. The epidemiology of plant diseases also will be altered. Prediction of disease outbreaks will be more difficult in periods of rapidly changing climate and unstable weather. Environmental instability and increased incidence of extreme weather may reduce the effectiveness of pesticides on targeted pests or result in more injury to nontarget organisms. Biological control may be affected either negatively or positively. Overall, the challenge to agriculture from pests probably will increase. Plant responses to ultraviolet radiation include reduced leaf size, stunted growth, poor seed quality, and increased 
susceptibility to weeds, disease, and pests. Climate change may bring new opportunities (e.g. new crop options), but also will pose new risks and challenges for farmers and specifically:

- Invasive insect, disease and weed pests are likely to benefit most from climate change, leading to increased pesticide and herbicide use;

- Reductions in biodiversity are likely, because climate change will tend to favor aggressive invasive at the expense of endangered species that are poor at migrating and adapting to change.

\section{Climate Variability}

Increased variability in rainfall and changes in temperature will likely disrupt key ecosystem processes such as phonology and will influence insect pests and diseases in mostly unknown ways. Direct effects on pests will involve disruption of insect life cycles or creation of more suitable conditions for new pests (or for old pests to expand their territory). Extreme meteorological events, such as spells of high temperature, heavy storms, or droughts, disrupt crop production. Recent studies have considered possible changes in the variability as well as in the mean values of climatic variables.

Agricultural systems are vulnerable to climate extremes, with effects varying from place to place because of differences in soils, production systems, and other factors. Changes in precipitation type (rain, snow, or hail), timing, frequency, and intensity, along with changes in wind (windstorms, hurricanes, and tornadoes), are likely to have significant consequences. Heavy precipitation events cause erosion, water logging, and leaching of animal wastes, pesticides, fertilizers, and other chemicals into surface and groundwater.

\section{Pesticide Movement in the Environment}

Trans-boundary movement of toxic substances through natural and man-made pathways and their worldwide use in agriculture and escalation of industrial activities to countries with cheaper labor, pose a threat to human beings and environment of the countries of this region which are hardly prepared to tackle their adverse consequences. Trans-boundary transport of chemicals is known since long back. Once applied pesticides disperse from the point of application and become redistributed, some on global scale. Organo-chlorine insecticides such as DDT have been detected in the Arctic as well as in the mid Pacific Ocean. They are long-lived and spread through the atmosphere mostly as spray drift which adheres to dust and is transported thousands of kilometers by global wind currents. Endosulfan is extensively used in Nepal. It is banned in Sri Lanka, Pakistan and in other Gulf countries. The chemical, in view of its properties is categorized as with low long-range transport potential.

\section{Consequences of Climate Change}

Climate change is a unique, global, long-term problem, involving complex interactions. Regional changes in climate, particularly increases in temperature, have already affected some physical and biological systems. Both natural and human systems are vulnerable to climate change because of their limited adaptive capacity. This vulnerability varies with geographic location, time, and social, economic and environmental conditions

In what way could Climate Change affect us in the future and how serious could the consequences be? Climate change was real and the consequences could not be ignored. Negative consequences of climate change include effects on pesticide use, run-off of nutrients and potential regional conflicts for some groundwater sources. Pesticides are toxic to many forms of life. Beneficial insects such as ladybugs and honeybees can be killed by pesticides which can lead to worse insect problems in the future. 
Man will have to adapt to and cope with the climate change consequences that are not prevented by mitigation. Economic losses can be expected, especially in poorest regions; the higher the warming, the greater the losses. Some other important changes include precipitation, cloud cover and extreme temperatures. Promoting adaptation, sustainable development and equity can be mutually reinforcing.

\section{Adaptation Strategies}

A wide variety of adaptive actions may be taken to lessen or overcome adverse effects of climate change on agriculture. At the level of farms, adjustments may include the introduction of later- maturing crop varieties or species, switching cropping sequences, sowing earlier, adjusting timing of field operations, conserving soil moisture through appropriate tillage methods, and improving irrigation efficiency. Some options such as switching crop varieties may be inexpensive while others, such as introducing irrigation (especially high-efficiency, water-conserving technologies), involve major investments Adaptation cannot be taken for granted: improvements in agriculture have always depended upon on the investment that is made in agricultural research and infrastructure. It would help to identify, through research, the specific ways that farmers now adapt to present variations in climate. Adaptations such as changing planting dates and choosing longer season varieties are likely to offset losses or further increase yields.

The wide uncertainties in climate scenarios, regional variation in climate effects, and interactions of environment, economics, and farm policy suggest that there are no simple and widely applicable adaptation prescriptions. Farmers will need to adapt broadly to changing conditions in agriculture, of which changing climate is one factor. It is difficult to predict accurately what adaptations people will make. This is particularly challenge since adaptations are influenced by many factors, including government policy, technology research and development, and agricultural extension services.

\section{Policy Issues}

- Increasing concern over the environmental impacts of pesticide use, as evidenced by multilateral environmental agreements such as the Stockholm Convention on POPs, denotes the urgent need for management of pesticides.

- While confronting the challenge of climate change will ultimately require comprehensive national policy and international agreements, the states and regions have a valuable role to play.

- Educate key policy makers and the public about the causes and potential consequences of climate change and assist the domestic and international communities in developing practical and effective solutions to this important environmental challenge.

\section{Mitigation of Climate Change}

- Reduce grower input cost

A strong need to reduce grower input cost with concomitant increase in yield and quality with reduced environmental impact is the need.

- Minimizing the hazards and risks

Minimize the hazards and risks from the use of pesticides.

- Improved controls 
Improved controls on the use and distribution of pesticides.

- Substitution principle

Application of the substitution principle.

- Low-input

Encouraging low-input or pesticide free crop farming.

- International aspect:

Implementing Rotterdam Convention on Prior Informed Consent (PIC) and Stockholm Convention on Persistent Organic Pollutants (POPS)

- Gender and environment

Consider fully gender and environment issues in all aspects of development and management in agriculture.

- Use of ODS

Better not to use/consume ODS according to the time schedule of the Montreal Protocol. Alternative, affordable chemicals exist for all the ozone- damaging chemicals, and these substitutes don't harm the ozone layer.

- Codes of Practice/Pesticides Management Code

These Codes do not have a legal basis, but serve to establish acceptable standards of conduct for the users as well as the public and private sectors. Codes have been adopted for a range of topics including the Safe Handling of Pesticides, Safe Disposal of Surplus Pesticides, the Application of Fumigants, etc. Codes of practice suggest to follow Pesticide Use Rules, Sale Rules and Layout rules for the storage, loading and unloading of pesticides.

- Organic farming methods

Organic farming methods combine scientific knowledge and modern technology with traditional farming practices based on thousands of years of agriculture. In general, organic methods rely on naturally.

\section{Conclusion and Recommendation}

- Government and Non-government Organizations (NGOs) need to promote programs on education about basic pesticide use, concept of eco-friendly farming and also global warming, which will ensure long-term food security and environmental safety.

- Create increased awareness of change in the context of agricultural, environmental and health policies.

- To address the range of problems identified above, much needs to be done to enhance $R$ and $D$ to support pesticide reduction for agriculture, animal husbandry and public health and to strengthen capacity in developing countries to develop regular monitoring systems with objectively verifiable indicators (OVIs) and research capacity to deal with the problems of chemical pesticides and climate change.

- Our goal should be directed towards healthy communities and ecosystems and

- Greatly enhanced efforts should be implemented to understand the relationship between pesticide use and climate for crops in the tune of protecting, sustaining or restoring the health of people, communities and ecosystems using integrated and comprehensive approaches and partnerships. 
- The analysis of biodiversity externalities from the standpoint of economic analyses is also unsatisfactory and need rigorous analyses. To assess the relationship between pesticide usage and climate change for crops in Nepal, the exiting knowledge and data-base are inadequate and more extensive studies are needed on both aspects: measurements/monitoring and modeling.

- In effective transfer of technologies bilateral, regional multinational and global networking of activities is an essential part that is often given less attention. The international agencies can play an effective role in this aspect.

- The valuation of externalities should be expressed in monetary terms whenever the available data and methodology considerations allow.

\section{REFERENCES}

1. Green Facts: Fact on Health and the Environment 2007: IPCC Assessment Report on Scientific Facts on Climate Change and Global Warming

2. Karmacharya. J., March/April 2007:"Regional Climate Projection and Regional climate Model ", Namaste Nepal, Year 15, Vol.2, pp 8

3. Palikhe.B.R.,2003:"Pesticides as water Pollutants", Agriculture and Environment Journal, pp 20

4. Palikhe.B.R.,2002: "Pesticide and Environment", Agriculture and Environment Journal, pp 38

5. James J. et al.2001: Impacts, Adaptations, and Vulnerability, pp 562

6. Rubin, E. et al. 1992: Realistic mitigation options for global warming, Science 257, 148.

7. Pimentel, D. 1991: Diversification of biological control strategies in agriculture. Crop Protection 10, pp 243-253. 